Research Article

\title{
Performance and Microstructural Analysis of Lightweight Concrete Blended with Nanosilica under Sulfate Attack
}

\author{
Paola Vargas, ${ }^{1,2}$ Natalia A. Marín, ${ }^{1,3}$ and Jorge I. Tobón (iD) ${ }^{1}$ \\ ${ }^{1}$ Department of Materials and Minerals, Cement and Construction Materials Group (CEMATCO), \\ Universidad Nacional de Colombia, Medellín, Colombia \\ ${ }^{2}$ Department of Engineering, Universidad de Medellín, Medellín, Colombia \\ ${ }^{3}$ Universidad Católica de Oriente, Rionegro, Colombia \\ Correspondence should be addressed to Jorge I. Tobón; jitobon@unal.edu.co
}

Received 13 February 2018; Revised 10 April 2018; Accepted 2 May 2018; Published 3 June 2018

Academic Editor: Li Li

Copyright (c) 2018 Paola Vargas et al. This is an open access article distributed under the Creative Commons Attribution License, which permits unrestricted use, distribution, and reproduction in any medium, provided the original work is properly cited.

\begin{abstract}
The influence of two lightweight aggregates (LWA) on concrete and the effects of cement substitution for nanosilica (NS) on the interfacial transition zone (ITZ) and cementitious matrix of concrete in resistance to attacks by magnesium sulfate $\left(\mathrm{MgSO}_{4}\right)$ are researched in this work. The aggregates evaluated were perlite, which is a lightweight aggregate of open porous structure, and expanded clay (aliven) with closed porous structure. The variables included in the study were replacement percentage of coarse aggregates by lightweight coarse aggregates ( 0 and $100 \%$ by volume) and replacement percentage of cement by nanosilica ( 0 and $10 \%$ by weight). In the dosage of the mixtures, water/cementitious-material ratio constant of 0.35 was used. The LWA were characterized by XRD, XRF, and SEM techniques. Compressive strength, water absorption, and volume change in magnesium sulfate solution (according to ASTM C1012 for a period of 15 weeks) of lightweight concretes were evaluated. It was found that the nanosilica had effect on refinement in the pore system; however, the main incidence on the compressive strength and durability of lightweight concrete (LWC) was defined by the characteristics of lightweight aggregate used in its preparation.
\end{abstract}

\section{Introduction}

The durability of the conventional concretes under the chemical attack by sulfates has been studied according to the sulfate source; whether it is external or internal. The external attack occurs when the concrete is exposed to environments such as soil contaminated by sulfates or water with sulfate contents [1]. The internal attack is caused by issues such as excessive contamination with sulfate in concrete constituent materials, contaminated aggregates, or presence of sulfate in the cement clinker due to the use of sulfur-rich fuels or the presence of sulfides or sulfates in their raw materials [2]. The main consequence of the attack by sulfates is the disintegration of the concrete or mortar due to chemical reactions between the hydrated phases of the Portland cement and the sulfate ions. Depending on the concentration and source of the sulfate ions in the water and the cement composition, the expansion of the concrete can be produced, with the generation of cracks and increased permeability favoring the penetration of water with aggressive agents or the deterioration and loss of cohesion of the products of hydrated cement with progressive loss of compressive strength and mass [3].

Also, the durability of concrete under attack by sulfates according to the type of sulfate has been studied, finding that, in the traditional attack by sodium sulfate, as a consequence, the formation of secondary ettringite occurs. One of the main causes for this formation is due to the reaction between the $\mathrm{SO}_{4}^{2-}$ ions and the hydrated calcium monosulfoaluminate or to the formation of gypsum and its subsequent reaction with calcium aluminate hydrates $(\mathrm{C}-\mathrm{A}-\mathrm{H})$. While in the case of the magnesium sulfate attack, it attacks the calcium silicate hydrated (C-S-H) causing a loss of cohesion of the paste with the formation of gypsum, magnesium hydroxide, and silica gel as well [1].

Magnesium sulfate $\left(\mathrm{MgSO}_{4}\right)$ is the most aggressive of sulfates due to the lowering of the $\mathrm{pH}$ of the solution of the 
pores in the cement paste hydrated by the reaction with the portlandite and the formation of brucite [2]. $\mathrm{MgSO}_{4}$ reacts mainly with the hydration products of the cement; the reaction of the sulfate with calcium hydroxide released during the hydration of the cement forms calcium sulfates (gypsum, $\mathrm{CaSO}_{4} \cdot \mathrm{H}_{2} \mathrm{O}$ ) and magnesium hydroxide (brucite, $\mathrm{Mg}(\mathrm{OH})_{2}$ ), according to the following reaction [3]:

$$
\mathrm{MgSO}_{4}+\mathrm{Ca}(\mathrm{OH})_{2}+2 \mathrm{H}_{2} \mathrm{O} \rightarrow \mathrm{CaSO}_{4} \cdot 2 \mathrm{H}_{2} \mathrm{O}+\mathrm{Mg}(\mathrm{OH})_{2}
$$

Another possible effect of magnesium sulfate is the reaction with the C-S-H gel, where, due to the decalcification produced by this sulfate, a hydrated magnesium silicate is obtained, M-S-H, which is a poor cohesive gel [4], noncementitious, which leads to softening of the cement matrix $[5,6]$, according to the following reaction. In addition, as a result of this reaction, gypsum and hydrated silica are produced:

$$
\mathrm{C}-\mathrm{S}-\mathrm{H}+\mathrm{MgSO}_{4} \rightarrow \mathrm{CaSO}_{4} \cdot 2 \mathrm{H}_{2} \mathrm{O}+\mathrm{M}-\mathrm{S}-\mathrm{H}
$$

This gypsum, produced in (2), could react with C3A to produce ettringite, as shown in the following reaction [1]:

$$
\begin{gathered}
\mathrm{CaSO}_{4} \cdot 2 \mathrm{H}_{2} \mathrm{O}+\mathrm{Al}_{2} \mathrm{O}_{3} \cdot 3 \mathrm{CaO}+26 \mathrm{H}_{2} \mathrm{O} \\
\rightarrow \mathrm{Ca}_{6} \mathrm{Al}_{2}\left(\mathrm{SO}_{4}\right)_{3}(\mathrm{OH})_{12} \cdot 26 \mathrm{H}_{2} \mathrm{O}
\end{gathered}
$$

In the presence of carbonates and under the appropriate environmental conditions, the formation of thaumasite $\left(\mathrm{CaSiO}_{3} \cdot \mathrm{CaSO}_{4} \cdot \mathrm{CaCO}_{3} \cdot 15 \mathrm{H}_{2} \mathrm{O}\right)$ can be produced, as shown in the following reaction [3]:

$$
\begin{aligned}
n \mathrm{SiO}_{2} & \cdot \mathrm{H}_{2} \mathrm{O}+\mathrm{CaOH}+\mathrm{CaCO}_{3}+\mathrm{MgSO}_{4} \\
\rightarrow & \mathrm{CaSiO}_{3} \cdot \mathrm{CaSO}_{4} \cdot \mathrm{CaCO}_{3} \cdot 15 \mathrm{H}_{2} \mathrm{O} \\
& +\mathrm{CaSO}_{4} \cdot 2 \mathrm{H}_{2} \mathrm{O}+\mathrm{Mg}(\mathrm{OH})_{2}
\end{aligned}
$$

To fully appreciate lightweight concrete, it is essential to understand the intrinsic nature of lightweight aggregates (LWA) and how they influence the properties of concrete made from them. The LWA have an array of vesicles or air void within their mass. The size, spacing, and interconnection of the vesicles make these aggregates capable of producing concrete with lower density close to $1850 \mathrm{~kg} / \mathrm{m}^{3}$, with advantages such as increased thermal insulation, extended moist curing, and increased durability [7].

The effect of lightweight aggregates on both the microstructure and durability of mortars and concretes has been studied by several researchers [8-12]. Finding that light aggregates affect the microstructure of the interfacial transition zone (ITZ), of porous quality, which has been improved with the addition of fly ash and silica fume, finding that, in order to improve resistance to sulfate attack with these materials, the content of fly ash or natural pozzolan should be between 25 and $35 \%$ by mass, while for silica fume between 7 and 15\% (ACI 201-2) [13-15]. The addition of such materials significantly reduces the permeability of the concrete, and also when combined with the alkalis and the calcium hydroxide which are released during the hydration of the cement, the potential for gypsum formation reduces.
TABle 1: Chemical composition of materials.

\begin{tabular}{lcccc}
\hline \multirow{2}{*}{ Chemical composition } & \multicolumn{4}{c}{ Weight (\%) } \\
& Perlite & Aliven & NS & Cement \\
\hline Silicon oxide $\left(\mathrm{SiO}_{2}\right)$ & 72.45 & 59.67 & 93.56 & 20.9 \\
Titanium oxide $\left(\mathrm{TiO}_{2}\right)$ & 0.22 & 1.19 & 0.02 & 0.21 \\
Aluminum oxide $\left(\mathrm{Al}_{2} \mathrm{O}_{3}\right)$ & 13.38 & 16.95 & 0.00 & 4.72 \\
Iron oxide $\left(\mathrm{Fe}_{2} \mathrm{O}_{3}\right)$ & 1.35 & 9.79 & 0.39 & 3.20 \\
Magnesium oxide $(\mathrm{MgO})$ & 0.08 & 4.13 & 0.13 & 1.80 \\
Calcium oxide $(\mathrm{CaO})$ & 1.20 & 3.57 & 0.22 & 60.69 \\
Sodium oxide $\left(\mathrm{Na}_{2} \mathrm{O}\right)$ & 3.40 & 2.07 & 0.62 & 0.37 \\
Potassium oxide $\left(\mathrm{K}_{2} \mathrm{O}\right)$ & 4.57 & 1.28 & 0.02 & 0.61 \\
Sulfur oxide $\left(\mathrm{SO}_{3}\right)$ & 0.09 & 0.04 & 0.30 & 0.13 \\
Ignition losses at $1000^{\circ} \mathrm{C}$ & 2.92 & 0.75 & 4.46 & 3.68 \\
\hline
\end{tabular}

Nanosilica (NS) has been widely recognized as an active additive to cement $[16,17]$. Its activity accelerates the hydration reaction by means of the nucleation mechanism (early activity) for the formation of $\mathrm{C}-\mathrm{S}-\mathrm{H}$, and its pozzolanic activity increases the production of C-S-H. Additionally, NS also acts as a filler decreasing the water absorption that allows us to improve the durability of the cementitious matrix $[9,10]$.

This work focuses on the study of the morphology and composition (chemical and mineralogical) of the LWA, the replacement of cement by nanosilica in the formation of the microstructure and the thickness of the ITZ, and the influence of this on the resistance to attack by magnesium sulfate in lightweight concretes.

\section{Materials and Methods}

For the manufacture of concretes, ordinary Portland cement, nanosilica (NS), and two lightweight aggregates, thermally expanded clay aliven (AL) and perlite (PE), as well, were used.

The methodology proposed for the development of this research is divided into three main activities: chemical, mineralogical, and physical characterization of raw materials through X-ray diffraction (XRD), scanning electron microscopy (SEM), optical microscopy (OM), specific surface area (BET), and density and water absorption of aggregates (ASTM C 127 [18]). The second stage consisted in the design and preparation of the concretes and finally the study of the mechanical properties and durability of the LWC.

2.1. Chemical Characterization of Materials. The chemical composition of cement, nanosilica, perlite, and expanded clay was determined by X-ray fluorescence (XRF) using ARL $8680 \mathrm{~S}$ equipment in boron lithium oxide $\left(\mathrm{B}_{4} \mathrm{Li}_{2} \mathrm{O}_{7}\right)$ pills. In Table 1, it can be seen that silicon oxide is present in a greater proportion for both aggregates, being higher in perlite $(72.45 \%)$ than in aliven (59.67\%). The second component present in greater quantity in both aggregates is aluminum oxide, but unlike $\mathrm{SiO}_{2}$, aliven has a higher content of $\mathrm{Al}_{2} \mathrm{O}_{3}$ in comparison with the perlite. The NS used is of high purity. The main constituent of the cement is calcium oxide, present in $60.69 \%$, followed by $20 \%$ silicon oxide and lower presence of sulfur of interest in this research. The chemical 


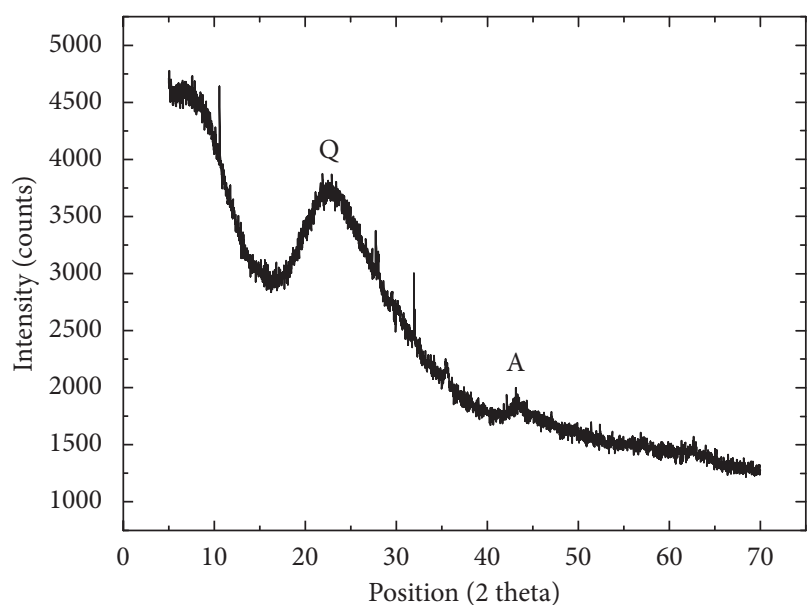

Q: quartz A: albite

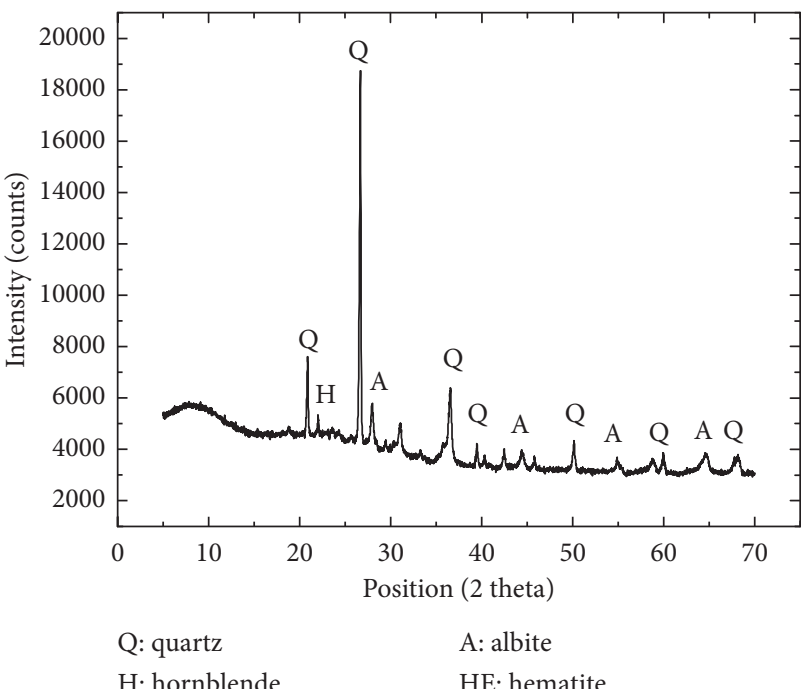

(b)

(a)

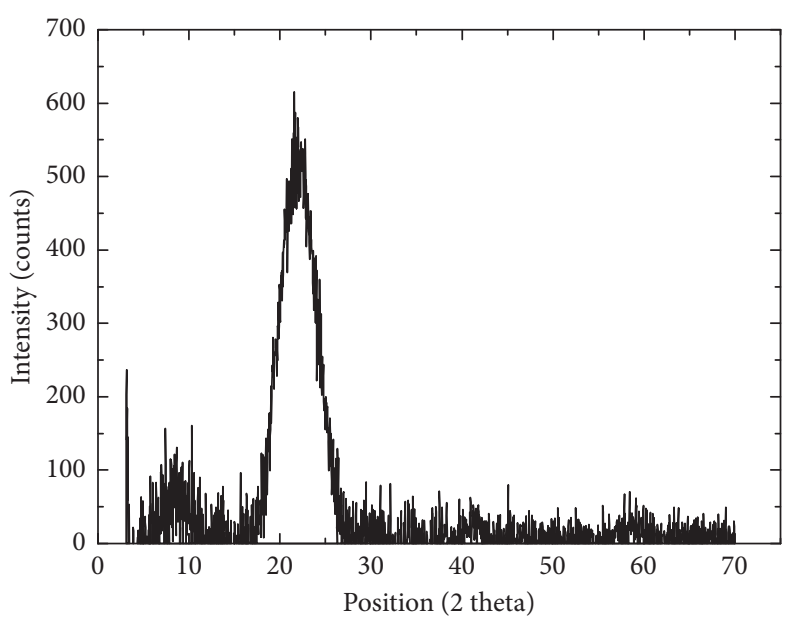

(c)

FIGURE 1: XRD patterns of (a) LWA perlite, (b) LWA aliven, and (c) nanosilica.

composition of the cement indicates that the percentages correspond to a Portland cement type I according to ASTM C 150 [19].

2.2. Mineralogical Characterization. The mineralogical characterization for aggregates and nanosilica was performed using X-ray diffraction (XRD) in an XRD PANalytical X'Pert Pro MPD with a copper $(\mathrm{Cu}) \mathrm{X}$-ray source $(\lambda \alpha 1=0.154059 \mathrm{~nm})$, in a $2 \theta$ interval between $6^{\circ}$ and $70^{\circ}$, with a step of $0.02^{\circ}$, and an accumulation time of $30 \mathrm{~s}$. The identification of diffractograms was done with the database of X'Pert High Score Plus software. For the perlite, it can be seen that, in the diffractogram of Figure 1(a), a broad peak is formed between positions $2 \theta$ of $20^{\circ}$ and $30^{\circ}$, where the characteristic quartz peak is found around $26.5^{\circ}$. This peak corresponds to silica of low degree of crystallinity or amorphous, characteristic attributed to the fact that this peak lacks the slenderness that indicates the high crystallinity of silica. Other minor components are aluminosilicates such as albite. This composition corresponds to the processes of perlite formation, which is a volcanic glass.

The diffractogram of Figure 1(b) allows us to establish that the main mineralogical species in the aliven, corresponding to high-grade crystallinity quartz, is in the position $2 \theta$ of $26.5^{\circ}$, and this peak has a great slenderness reaching the $y$-axis to approximately 18000 counts. Other phases present correspond to alumininosilicates in the form of plagioclase and hornblende and small traces of iron oxide in hematite form. This mineralogy of aliven corresponds with its origin of thermally expanded clay. For the nanosilica (Figure 1(c)), it is shown that it corresponds to silica nanoparticles of low degree of crystallinity.

2.3. Morphological Characterization. The morphology of the aggregates was studied by micrographs of stereoscopy and SEM, in JEOL JSM 5910LV with backscattering electrons (BES) detectors, and for nanosilica by TEM, in a FEI TECNAI 20 Twin microscope. Perlite (Figure 2), 

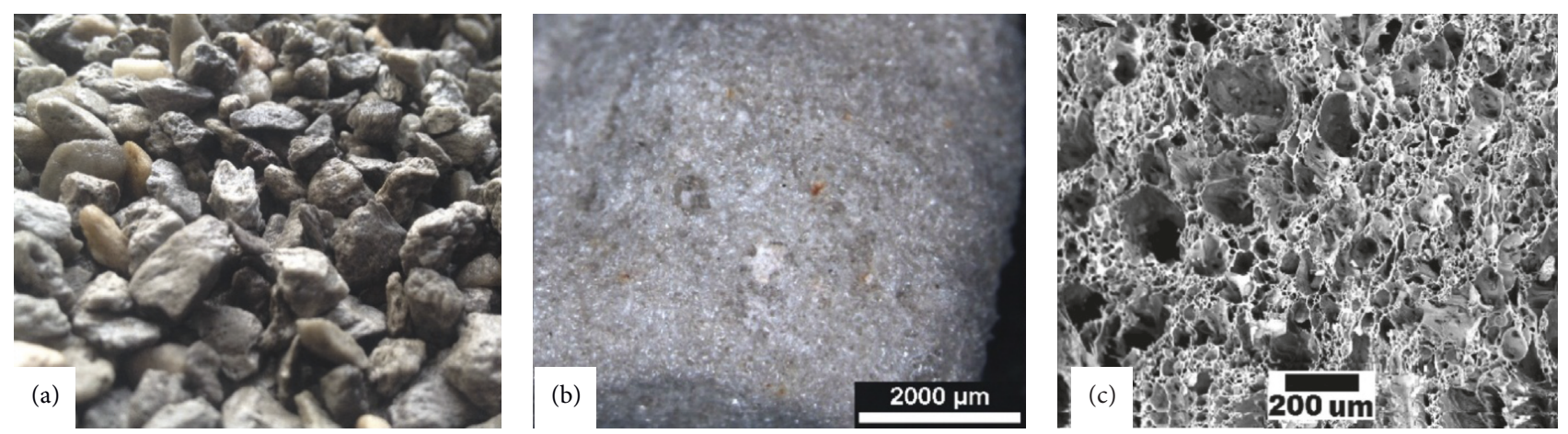

FiguRE 2: LWA perlite: (a) real scale; (b) micrograph to $32 \mathrm{x}$ and (c) SEM micrograph to 500x.
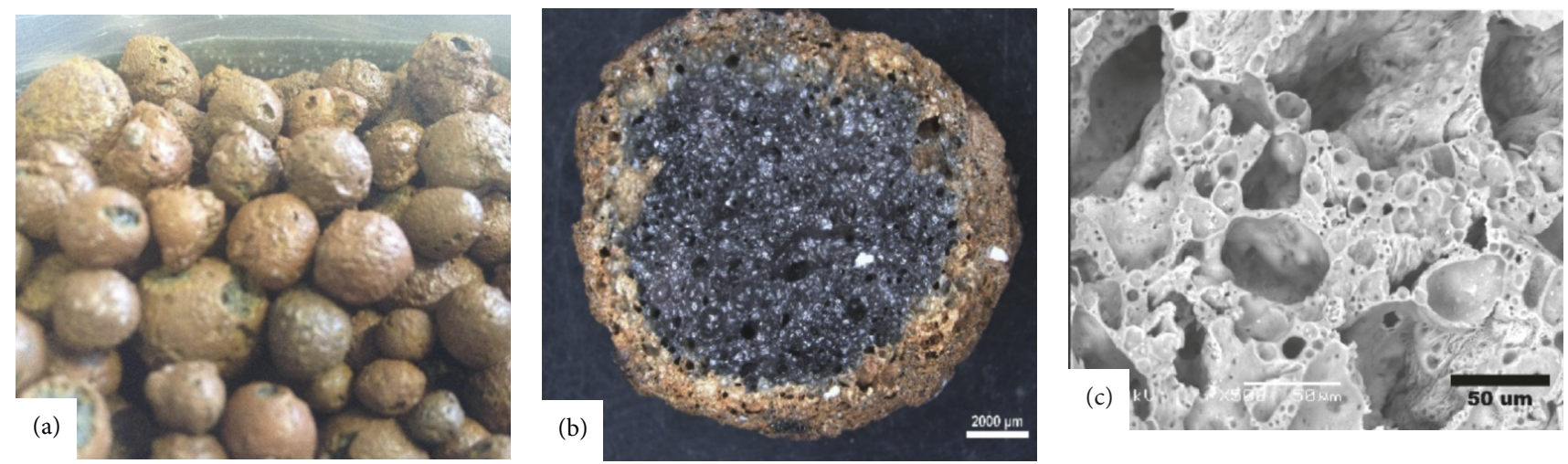

Figure 3: LWA aliven: (a) real scale; (b) micrograph to 32x and (c) SEM micrograph to 500x.

corresponding to an aggregate of angular volcanic origin with exposed and interconnected pores, is an aggregate of acidic rocks due to its light color and composition of $\mathrm{SiO}_{2}>65 \%$ [20]. The perlite structure allows it to retain large amounts of interstitial water.

The aggregate aliven (Figure 3) corresponds to a thermally expanded clay, spherically shaped, and rough surface, most of which are spheres with their porous interior, with some interconnected pores, surrounded by a brownish vitrified layer of varying thickness and smaller porosity (Figure 3(b)). In Figures 2(c) and 3(c), for perlite and aliven, respectively, the shape, size, and distribution of their pores can be appreciated. For nanosilica in Figure 4, individual spheres of particle diameters between $20 \mathrm{~nm}$ and $70 \mathrm{~nm}$ are observed.

2.4. Physical Characterization. The water absorption test was performed for each type of aggregate according to the specifications of ACI 211.2 and density according to ASTM C 127 [18], and this process consists of immersing the aggregate sample in water for 24 hours to essentially fill the pores. It is then removed from the water, the water dried from the surface of the particles, and the mass determined. Subsequently, the volume of the sample is determined by the displacement of water method. Finally, the sample is oven-dried and the mass

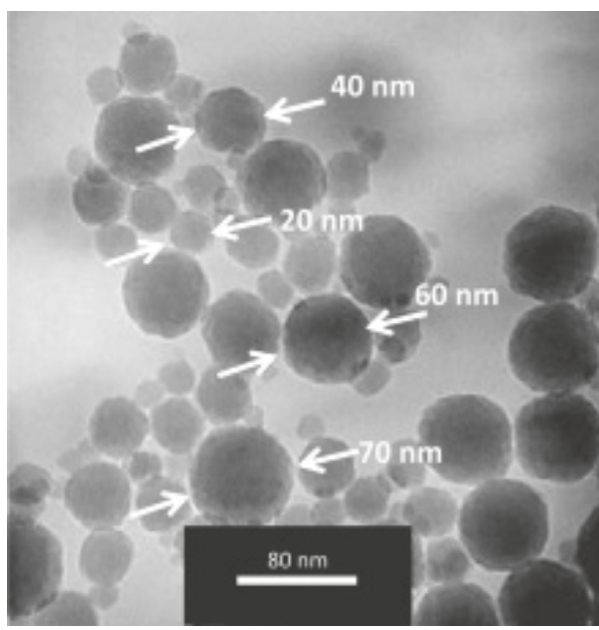

FIGURE 4: TEM micrograph of nanosilica.

determined. Using the mass values thus obtained and formulas in this test method, it is possible to calculate relative density and absorption.

Surface area was determined through the BET test by chemisorption. The water absorption of the LWA (Table 2) shows a higher absorption value for perlite due to its greater specific surface area and its open and exposed porosity and 
TABle 2: Physical properties of aggregates and NS.

\begin{tabular}{lccc}
\hline & $\begin{array}{c}\text { Surface area } \\
\left(\mathrm{m}^{2} / \mathrm{g}\right)\end{array}$ & $\begin{array}{c}\text { Apparent relative } \\
\text { density }\left(\mathrm{kg} / \mathrm{m}^{3}\right)\end{array}$ & $\begin{array}{c}\text { Water } \\
\text { absorption }(\%)\end{array}$ \\
\hline $\mathrm{PE}$ & 2.10 & 305.5 & 42.0 \\
$\mathrm{AL}$ & 1.13 & 519.9 & 10.3 \\
$\mathrm{NS}$ & 51.40 & 1.12 & - \\
\hline
\end{tabular}

characteristics that confer low densities of $305.5 \mathrm{~kg} / \mathrm{m}^{3}$. For the aggregate aliven, its density is $519.9 \mathrm{~kg} / \mathrm{m}^{3}$ because it is a porous material in its interior with the pore sizes of the order of $10 \mu \mathrm{m}$ to $500 \mu \mathrm{m}$, and the water absorption is lower because in the outer layer of its structure, the pore size is smaller than the capillary, thus inhibiting the migration of water into the aggregate (Figure $3(\mathrm{c}))$. NS has a large specific surface area according to its size, which is an indicator of its reactivity.

2.5. Preparation of Test Samples for Compressive Strength and Sulfate Attack. In the design of mixtures, two lightweight aggregates were used in the coarse state, through sieve $3 / 8^{\prime \prime}$, and retained in sieve no. 4 , perlite and aliven at a rate of $325 \mathrm{~kg} / \mathrm{m}^{3}$ of concrete, cement $500 \mathrm{~kg} / \mathrm{m}^{3}$ of concrete, water/cementitious-material ratio $(\mathrm{a} / \mathrm{mc})$ of 0.35 , and addition of $10 \%$ nanosilica in replacement by weight of the cement content.

From previous researches [7] and the literature review [11, 21-24], a ratio of $0.35 \mathrm{a} / \mathrm{mc}$ was selected, allowing good workability, so as not to require the use of a superplasticizer in the mixture, which could lead to modifications in the microstructure of the ITZ and cementitious matrix of interest in this study. The proportion of cement of $500 \mathrm{~kg} / \mathrm{m}^{3}$ is the product of the bibliographical revision; for which in some studies, compressive strength in LWC greater than $17.5 \mathrm{MPa}[7,21,25-27]$ was achieved. The use of $10 \%$ of nanosilica was due to the previous results [16], where it was observed that the optimal replacement of cement by suspended silica nanoparticles was in this percentage, since the compressive strength increased considerably, with respect to a control sample; in addition, the pore network in the cementitious matrix decreased and its tortuosity increased as well, which decreased the penetration of aggressive agents [16].

The concrete mixtures were made according to the selected parameters, and also cubic test samples were fabricated with $50 \mathrm{~mm}$ side, for unconfined compressive strength test and prismatic test samples of $25 \mathrm{~mm} \times 25 \mathrm{~mm} \times 285 \mathrm{~mm}$, as established by ASTM C157 M [28], to evaluate resistance to sulfate attacks. Once fabricated, the cubic test tubes were subjected to a wet curing process in water saturated with lime, at a room temperature of $23 \pm 2^{\circ} \mathrm{C}$, until the ages of 7 and 28 days, ages in which the compressive strength, the volume of pores, and the absorption of water were determined. The prisms for the concrete expansion test were cured under the same conditions for 28 days and then subjected to the attack of magnesium sulfate.

2.6. Immersion in Magnesium Sulfate. At the end of the normal curing time, the prisms were submerged for 15
TABLE 3: Compressive strength of LWC manufactured with perlite (PEC) and with aliven (ALC) to 7 and 28 days with and without addition of NS.

\begin{tabular}{lcc}
\hline Sample & $\begin{array}{c}\text { Compressive } \\
\text { strength at } \\
7 \text { days (MPa) }\end{array}$ & $\begin{array}{c}\text { Compressive } \\
\text { strength at } \\
28 \text { days (MPa) }\end{array}$ \\
\hline PEC5-0 & $8.1 \pm 1.9$ & $10.4 \pm 1.3$ \\
PEC5-10 & $12.4 \pm 3.4$ & $9.9 \pm 2.9$ \\
ALC5-0 & $23.8 \pm 0.1$ & $26.3 \pm 1.5$ \\
ALC5-10 & $15.2 \pm 2.5$ & $22.1 \pm 1.0$ \\
\hline
\end{tabular}

weeks in a 5\% mass solution of magnesium sulfate $\left(\mathrm{MgSO}_{4}\right)$, at $\mathrm{pH}=7$, to evaluate the attack of these sulfates, according to ASTM C1012 [29]. The longitudinal change of the prismatic test samples was measured after being submerged in the $\mathrm{MgSO}_{4}$ solution. The solution was changed monthly, and during weekly time intervals the $\mathrm{pH}$ was controlled to maintain it between 6 and 7 units.

\section{Results and Discussion}

3.1. Compressive Strength of Lightweight Concretes (LWC). The concretes manufactured with perlite and aliven were submitted to tests of compressive strength after 7 and 28 days of normal curing. In Table 3, the results for compressive strength of LWC with and without nanosilica are shown. The sample AL corresponds to the concretes manufactured with LWA aliven and the sample PE to concretes with perlite. C5 means that all concretes were made with a proportion of cement of $500 \mathrm{~kg} / \mathrm{m}^{3}$. Samples with $10 \%$ of nanosilica are ALC5-10 and PEC5-10. On the contrary, the samples without nanosilica are ALC5-0 and PEC5-0.

The best results of compressive strength correspond to the concrete manufactured with aliven, with the average values of $26.3 \mathrm{MPa}$ and $22.1 \mathrm{MPa}$ at 28 days of normal curing for concrete without and with addition of NS, respectively. While for perlite concretes, only 10.4 MPa without addition and 9.9 MPa with NS were achieved, and these values when taking into account the standard deviation were statistically equal. For perlite samples, the compressive strength results were statistically the same for both the ages evaluated and the percentages of NS used. This means that it is the perlite that limits the maximum compressive strength that these mixtures can reach. In both concretes, the addition of nanosilica is not reflected in an increase in the compressive strength because in LWC the fault is given first by the aggregate and not by the matrix $[21,30]$, as it happens in the conventional concretes. The concrete with the aggregate of aliven has a greater compressive strength because this aggregate is characterized by having a vitrified layer on its surface that gives it greater hardness as well as mechanical resistance.

3.2. Expansion of Concretes. Figure 5 shows the results of change in the length of all bars under sulfate attack. Until week 4 , all the samples have a very low expansion $(0.02 \%)$, but from this time, there is a clear difference in the behavior of the samples with perlite compared to the samples with aliven. The bars with perlite present an increasing expansion 


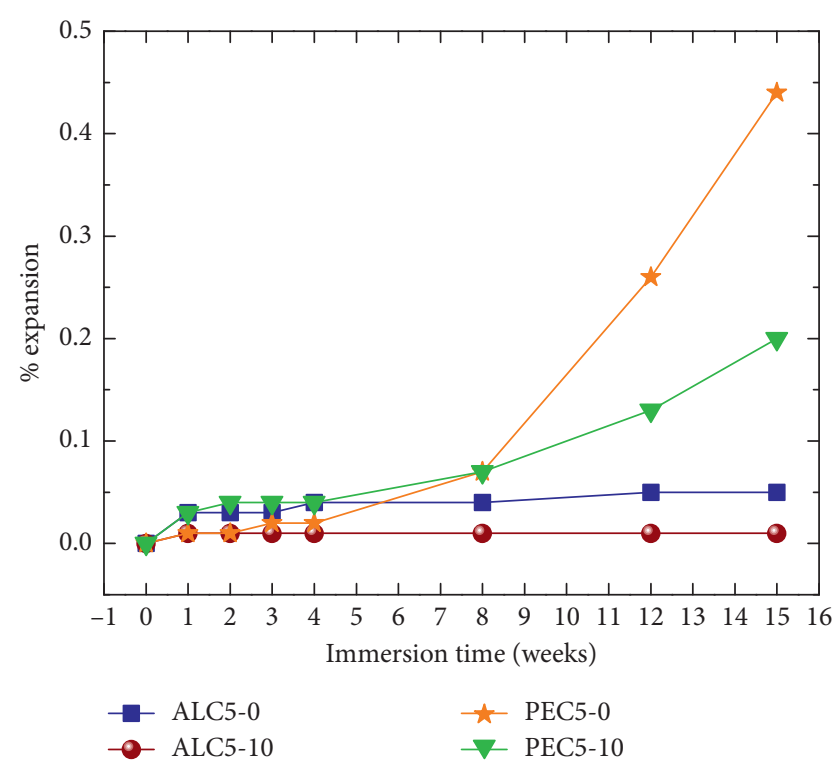

FIgURE 5: Length change of LWC ALC5 and PEC5 with and without addition of $10 \%$ nanosilica.

with the time of immersion in sulfates, reaching values of $0.44 \%$ for PEC5-0 and $0.2 \%$ for PEC5-10 in the 15 weeks tested. However, the samples with aliven show practically no expansion $(0.05 \%)$ during the whole time evaluated.

For concretes made with both perlite and aliven, samples with a $10 \%$ of nanosilica blended exhibit better behavior to attack by magnesium sulfate, with the perlite aggregate concrete being the weakest. These results are in accordance with the results of Tobón et al. [31], who analyzed the behavior of normal weight Portland cement mortars blended with nanosilica when they are subjected to attack of this kind of sulfate. These researchers showed how 5\% replacement of Portland cement by nanosilica, in these mortars, practically controls the expansion by the attack of sulfates. This can be explained from different points of view: First, the concretes with NS undergo a refinement of the pore structure [13]. Second, the perlite alumina may be more reactive and susceptible due to its volcanic origin to this attack than the one exhibited in the aliven. Because, as some authors have suggested $[32,33]$, the reactivity of the alumina present in the mineral additions is critical in the durability of the cementitious mixtures manufactured with them. Third, although the alumina content of the perlite is lower compared to that of the aliven, the alumina in the perlite is more exposed to this attack due to its surface porosity.

In accordance with ASTM C 1157 [34], a conventional concrete manufactured with a cement of moderate resistance to sulfates admits a maximum value of $0.10 \%$ of expansion. Therefore, the lightweight concrete manufactured with aliven as a coarse aggregate presents a performance against the attack by sulfates similar to those expected by a conventional concrete.

3.3. Pore Volume and Water Absorption. The pore volume and water absorption for the concretes studied were determined
TABLE 4: Volume of voids and water absorption of concretes manufactured with perlite (PEC) and with aliven (ALC) with and without addition of NS.

\begin{tabular}{lcc}
\hline Sample & Volume of voids (\%) & Water \\
\hline PEC5-0 & 32.4 & 36.2 \\
PEC5-10 & 31.3 & 34.2 \\
ALC5-0 & 24.1 & 22.9 \\
ALC5-10 & 23.4 & 21.9 \\
\hline
\end{tabular}

at 28 days of curing and in accordance with ASTM C 642 [35], for which the pore volume corresponds to the water saturable pores of the concrete, aggregate porosity, and cementitious matrix. Table 4 shows that for the aliven concrete the pore volume is significantly lower, between $23.4 \%$ for ALC5-10 and $24.1 \%$ for ALC5-0. For the perlite concretes, it is of the order of $32.4 \%$ for PEC5-0 and 31.3\% for PEC5-10. This behavior indicates that the nanosilica can reduce pore volume in LWC, $3 \%$ in aliven concrete and $3.3 \%$ in perlite. However, it can be established from the results obtained that the volume of pores in the LWC depends to a large extent on the morphology and type of porosity of the LWA. Concretes manufactured with porous surface aggregates and interconnected pores in the interior, such as perlite, which possess greater water absorption (42\%, Table 2 ) result in concretes with the greater volume of permeable pores, whereas concretes with aggregates of lower water absorption as aliven (10.3\%, Table 2 ) have a lower volume of pores.

The results of water absorption (Table 4) of concretes with aliven have a lower percentage of water absorption than those manufactured with perlite. In both concretes, the behavior for water absorption is decreasing by adding $10 \%$ of nanosilica and the same order of pore volume results.

The addition of nanosilica affects the water absorption of light concrete; although the concrete has a considerable volume of pores mainly attributed to the aggregates, the cementitious matrix is densified by the addition of NS, thus inhibiting the interconnection of pores that allow the migration of water from the matrix to the aggregate and consequently decreasing the water absorption in a low proportion of the order of $4.3 \%$ for the concrete of added aliven and $5.2 \%$ in the perlite concrete added with NS. The samples with the lowest percentage of expansion are those with NS in their formulation (ALC5-10 and PEC5-10).

It can be stated that both the pore volume and the water absorption of the LWC are reduced with the addition of NS, but they are conditioned mainly by the type of LWA used. Thus, in this case, using light aggregates with porosity and interconnected pores as perlite, LWC are obtained with higher volume of pores and greater water absorption, which is reflected in concrete with less mechanical resistance to compression and less durability in terms of resistance to the attack of the sulfates.

3.4. Morphology of Concretes Exposed to Attack by Sulfates. After the 15 weeks of exposure to magnesium sulfate, it can be seen that the perlite concretes are affected to a greater extent by magnesium sulfate, causing a warpage of $3.25 \mathrm{~mm}$ in the exposed joints of nonadded concrete (Figure 6(a)) and $2.75 \mathrm{~mm}$ for joints of added concrete (Figure 6(b)). When 


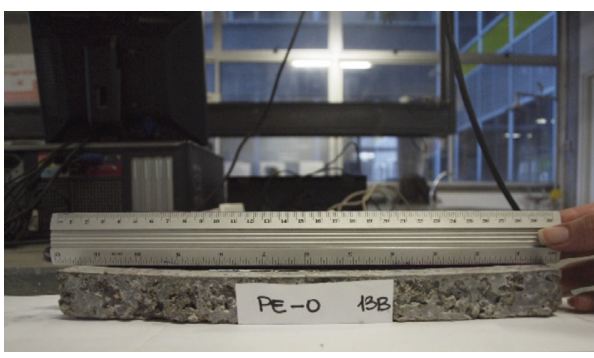

(a)

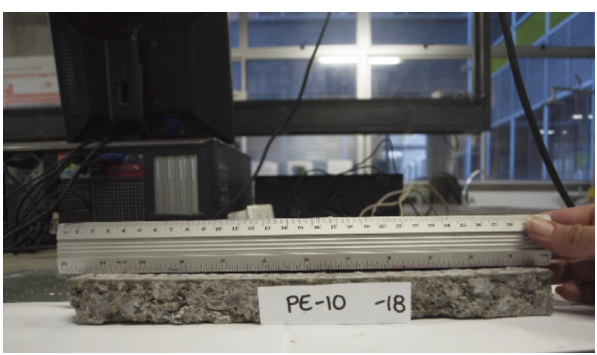

(b)

Figure 6: Concrete exposed to $\mathrm{MgSO}_{4}$ : (a) PEC5S-0 and (b) PEC5S-10.

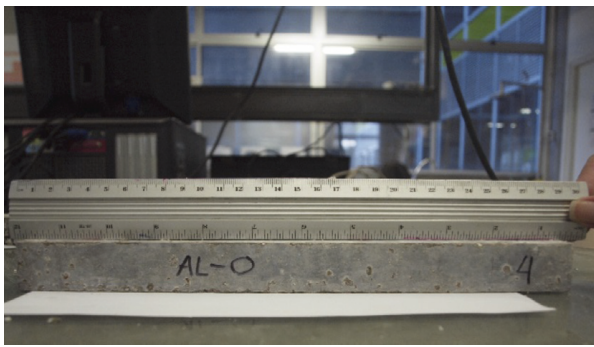

(a)

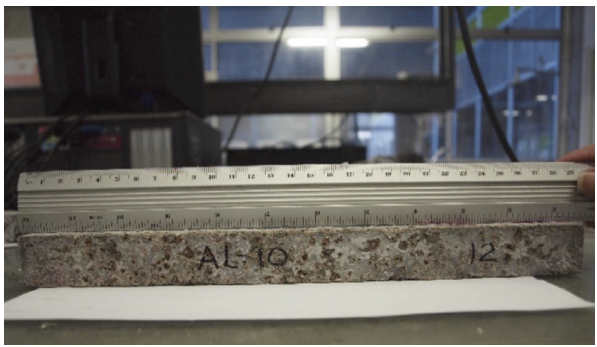

(b)

Figure 7: Concrete exposed to $\mathrm{MgSO}_{4}$ : (a) ALC5S-0 and (b) AlC5S-10.

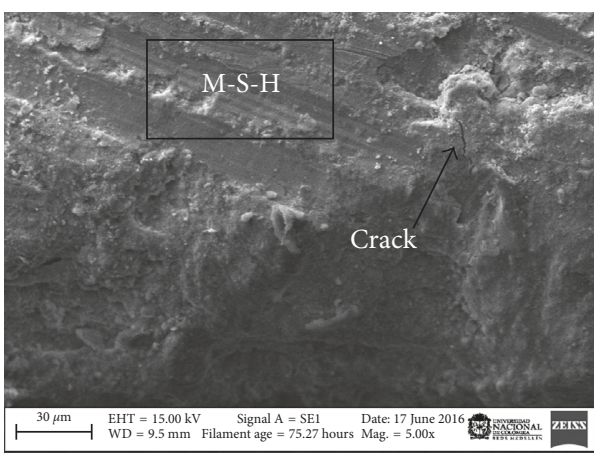

(a)

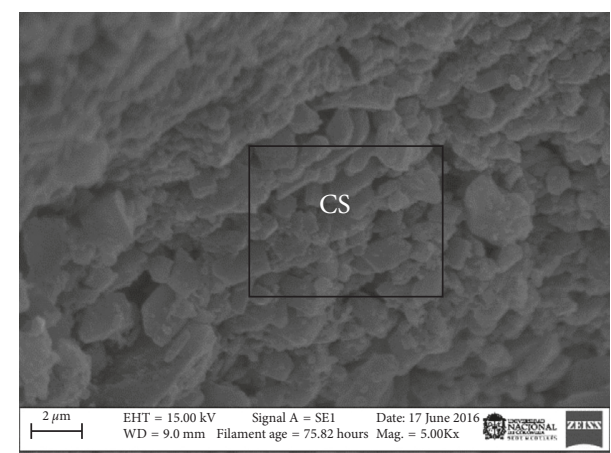

(b)

Figure 8: Border to the specimen of (a) ALC5S-0 and (b) AlC5S-10.

looking at aliven concretes, only the nonadded samples exhibit a slight warpage behavior, around $0.8 \mathrm{~mm}$ (Figure $7(\mathrm{a}))$, while the nanosilica-added concrete remains intact (Figure $7(b)$ ). This warpage behavior reflects the longitudinal change produced by the expansion of the concrete, thus validating the expansion results of Figure 5.

In addition, it can be seen that the sample added with nanosilica (Figure $7(\mathrm{~b})$ ) presents a greater surface degradation than the sample not added (Figure 7(a)). As is known, the nanosilica reacts with $\mathrm{Ca}(\mathrm{OH})_{2}$ forming a C-S-H gel; as there is more of this gel, $\mathrm{MgSO}_{4}$ could eventually react with it forming $\mathrm{M}-\mathrm{S}-\mathrm{H}$ on the surface, causing the deterioration observed in the image since that this product, as mentioned, has a low cohesion [4].

To identify the cause of warping and expansion of concretes, micrographs were taken at the edge of the beam for aliven concretes (Figure 8), in the ITZ (Figure 9) and inside the aggregate (Figure 10).

In Figure 8(a), it can be seen that the edge of the concrete sample of aliven without addition of nanosilica shows cracks. Through EDX, the elemental chemical composition on the surface was identified, with the presence of calcium (30\%), silica (7\%), sulfur (11\%), magnesium (5\%), and oxygen (45\%) on the surface (Figure 11). This chemical composition corresponds mineralogically to the transformation of C-S-H to $\mathrm{M}-\mathrm{S}-\mathrm{H}$, and other mineral phases present (Figure 8) that due to the chemical composition, it can be concluded that gypsum is formed $\left(\mathrm{CaSO}_{4}\right)$ which for graphic effects will be abbreviated as CS [10].

When analyzing the ITZ of the concretes attacked by $\mathrm{MgSO}_{4}$, in aliven concretes, mainly the presence of CS and $\mathrm{C}-\mathrm{S}-\mathrm{H}$ (Figure 9) is observed. Once $\mathrm{MgSO}_{4}$ permeates the 


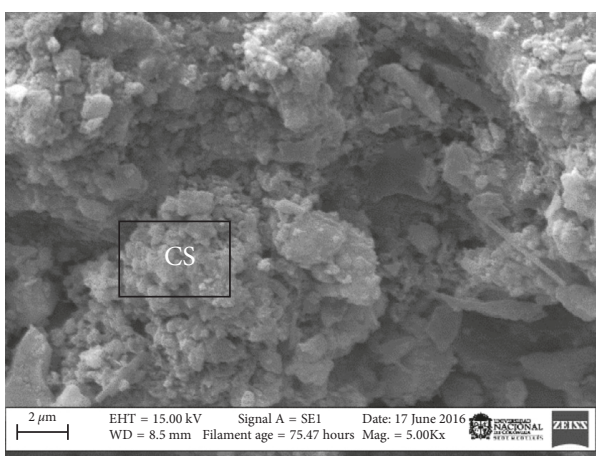

(a)

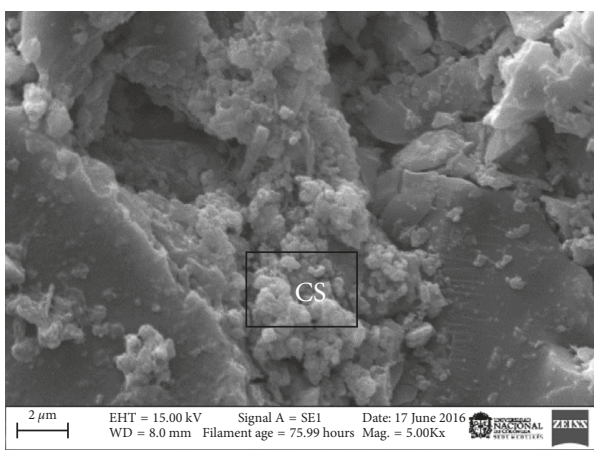

(b)

Figure 9: ITZ of (a) ALC5S-0 and (b) AlC5S-10.

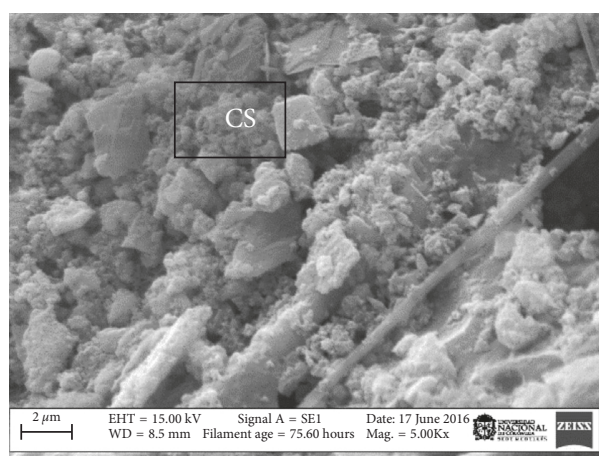

(a)

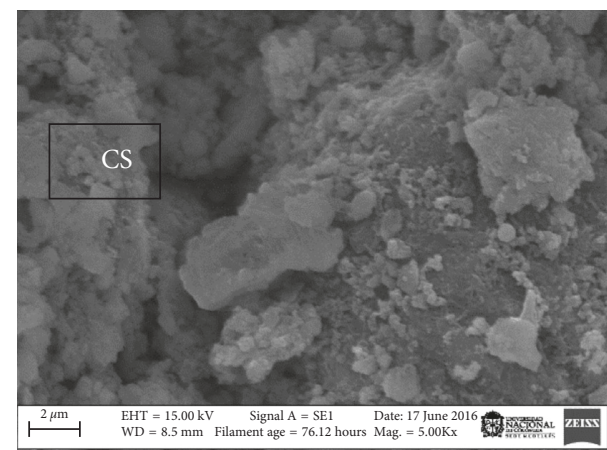

(b)

Figure 10: Aggregate zone of (a) ALC5S-0 and (b) AlC5S-10.

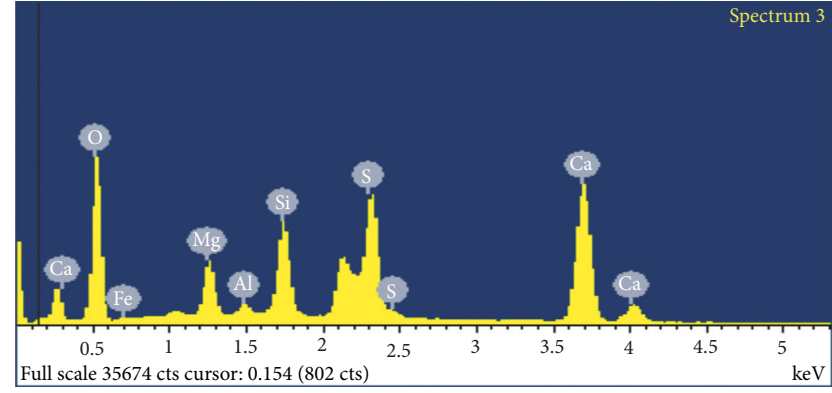

Figure 11: EDX on the border to the specimen of ALC5S-0.

interior of the aggregates, in the case of aliven, it is observed by EDS that the main composition corresponds to oxygen in $52 \%$, silicon $21.25 \%$, aluminum $12.32 \%$, and low values of calcium, iron, and magnesium. Such composition corresponds to the aggregate that is an aluminosilicate, but the amounts of magnesium are due to the deposition of low amounts of M-S-H by migration of sulfate to the interior due to the porosity of the aggregate (Figure 10). As can be seen in the micrographs, the disappearance of $\mathrm{CH}$ causes a drop in $\mathrm{pH}$ in the pores, which is sufficient to cause the decomposition of $\mathrm{C}-\mathrm{S}-\mathrm{H}$ and thus provide the active silica necessary for the formation of M-S-H [14].

For the perlite concretes (Figure 12), the same behavior is observed at the edge as for the aliven concretes. In the ITZ
(Figure 13), there is a presence of $\mathrm{M}-\mathrm{S}-\mathrm{H}$ by degradation of $\mathrm{C}-\mathrm{S}-\mathrm{H}$, gypsum, and ettringite in the case of concrete with the addition of nanosilica, which is appreciable as prismatic crystals. This ettringite can be produced by the reaction between $\mathrm{C} 3 \mathrm{~A}$ and gypsum, formed from the reaction of $\mathrm{C}-\mathrm{S}$ $\mathrm{H}$ and $\mathrm{Mg}(\mathrm{OH})_{2}$, according to (2).

Inside the aggregates of the perlite concrete can be noticed the presence of gypsum crystals (CS) (Figure 14). By EDX, the elemental composition corresponds mainly to oxygen, silicon, calcium, sulfur, and aluminum. Minor trace amounts of magnesium were also found to a lesser extent. Due to its porous structure, magnesium sulfate permeates the concrete until the interior of the aggregate.

As mentioned above, when $\mathrm{CH}$ reacts with $\mathrm{MgSO}_{4}$ in the presence of water, according to [36], gypsum and brucite are formed, but the pozzolanic addition, in the case of nanosilica, avoids the production of brucite but not the decalcification of the C-S-H because NS consumes calcium hydroxide, which is not available for the production of magnesium hydroxide or brucite. This can be observed in the micrographs of Figures 8,12, and 13, where there is no evidence of hexagonal brucite crystals but there are $\mathrm{M}-\mathrm{S}-\mathrm{H}$.

In this study, the aggregate of perlite presented higher water absorption, which led to a concrete with greater permeability and pore volume. Because of this, when using this type of lightweight aggregate, its high porosity content 


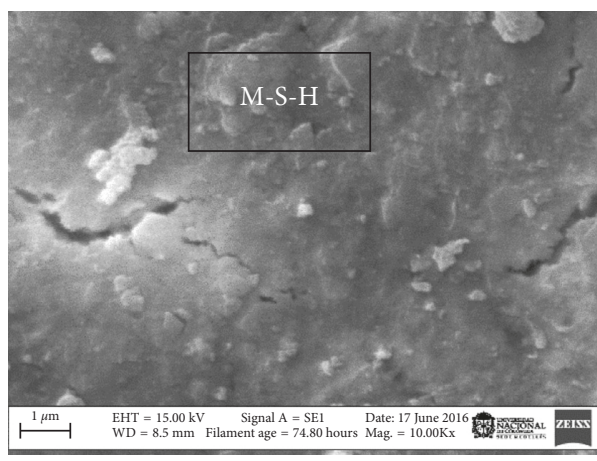

(a)

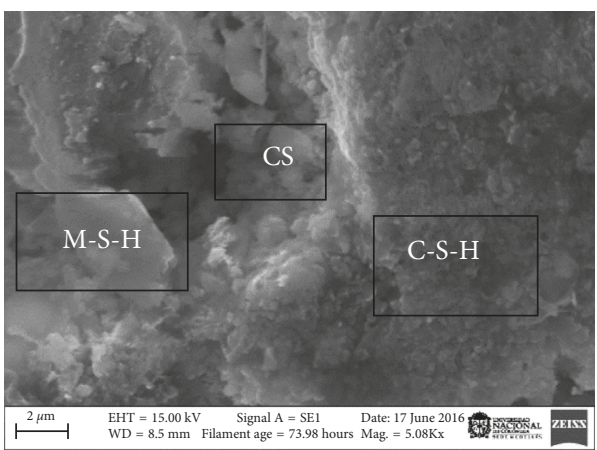

(b)

FIgure 12: Border to the specimen of (a) PEC5S-0 and (b) PEC5S-10.

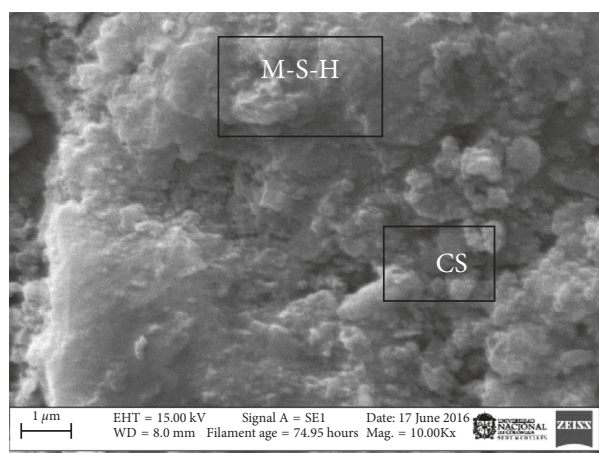

(a)

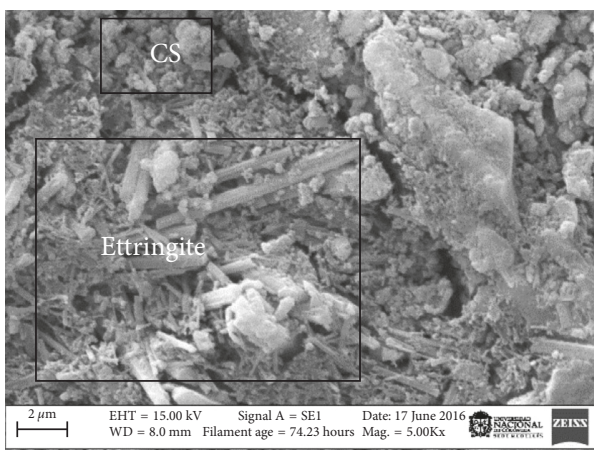

(b)

Figure 13: ITZ of (a) PEC5S-0 and (b) PEC5S-10.

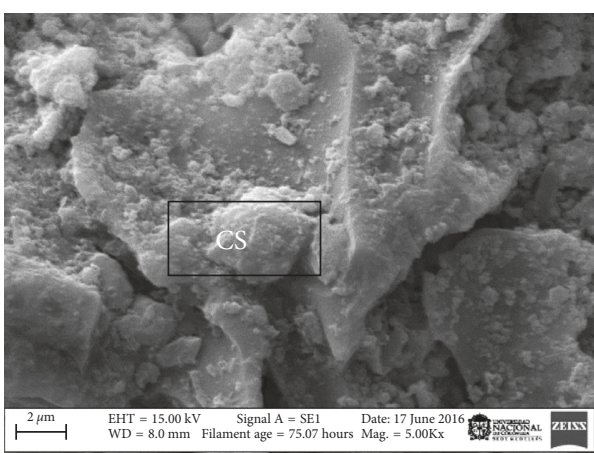

(a)

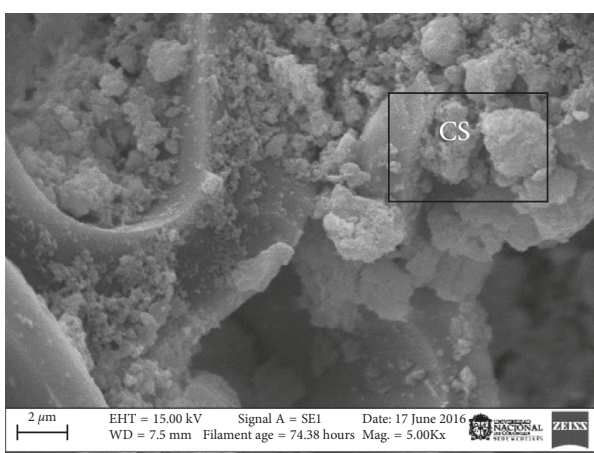

(b)

Figure 14: Aggregate zone of (a) PEC5S-0 and (b) PEC5S-10.

must be taken into account and also that these pores are usually interconnected. When subjecting this concrete to the sulfate attack, it was found to have a high degree of expansion, notorious after eight weeks of immersion, due to its high permeability and most likely to the presence of reactive alumina. The substitution of cement by $10 \%$ of nanosilica allowed us to densify the matrix and reduce the porosity and permeability of the concrete manufactured with this aggregate, which was reflected in a smaller expansion of this one compared to the concrete without the replacement of the cement. Unlike perlite, aliven presented smaller expansion, both with the replacement of the cement by $10 \%$ of nanosilica, as without this one. This behavior is due to the lower water absorption of the aggregate and to that it produces a concrete with a permeability and pore volume considerably lower than that produced with perlite.

\section{Conclusions}

The greatest expansion of lightweight perlite concretes is attributed to the direct migration of magnesium sulfate to the aggregate because it is an open porous surface aggregate 
versus aliven porous structure covered by a vitrified layer of low permeability porosity, and this migration of the sulfate ion allows the degradation of the C-S-H transforming it into $\mathrm{M}-\mathrm{S}-\mathrm{H}$ and in turn allowing the formation of gypsum that is responsible for expanding the concrete leading to the point of warping of concrete test tubes without the addition of nanosilica.

The use of nanosilica in the LWC refines the pore structure in the cementitious matrix as well as in the ITZ by increasing the formation of C-S-H, but this densification of the cementitious matrix is not high enough to impede the migration of water and sulfate ions from the exterior to the interior of the concrete until reaching the aggregate, as can be seen in the case of perlite.

The use of nanosilica decreased the expansion in the concretes preventing the formation of brucite because, when there is a reaction between $\mathrm{CH}$ and nanosilica, there is little $\mathrm{CH}$ available for the reaction with magnesium sulfate and the subsequent formation of brucite (MH).

Factors such as aggregate porosity and chemical composition are more important in the durability of lightweight concretes; despite the refining of the cementitious matrix with the addition of nanosilica, the absorption capacity of these aggregates favor the migration of the sulfate solution from the outside to the inside, concentrating and achieving that it affects the whole cementitious matrix and not only the exposed surface of the concrete.

The mechanism of reaction against chemical attack by magnesium sulfate for lightweight concretes is similar to the mechanism in conventional concretes where the attack occurs mainly on the C-S-H, but it has the aggravating circumstance that this attack can be enhanced by the type of lightweight aggregate that has been used, that is to say, with exposed porosity as perlite or closed porosity as calcined clay.

A concrete manufactured with lightweight aggregates of closed porosity, as the calcined clay, can show a similar performance to the conventional concrete against the aggressive sulfate attack like the magnesium sulfate; due to the exhibition of less expansion than $0.10 \%$, this value is suitable in standard for a conventional concrete, considering the behavior of this lightweight concretes to the compression strength.

\section{Data Availability}

The data used to support the findings of this study are available from the corresponding author upon request.

\section{Conflicts of Interest}

The authors declare that they have no conflicts of interest.

\section{Acknowledgments}

This work had been endorsed by the "National Program of Projects to Strengthen Research, Development and Innovation in Postgraduate Studies at Universidad Nacional de Colombia," Code 30474.

\section{References}

[1] M. Collepardi, "A state-of-the-art review on delayed ettringite attack on concrete," Cement and Concrete Composites, vol. 25, no. 4-5, pp. 401-407, 2003.

[2] P. K. Mehta and P. J. M. Monteiro, Concrete: Microstructure, Properties and Materials, McGraw-Hill Education, New York, NY, USA, 3rd edition, 2006.

[3] V. Rheinheimer, Sulphate Attack and the Role of Thaumasite in Historical Constructions, Technical University of Cataluña, Barcelona, Spain, 2008.

[4] M. Santhanam, M. D. Cohen, and J. Olek, "Mechanism of sulfate attack: a fresh look: part 1: summary of experimental results," Cement and Concrete Research, vol. 32, no. 6, pp. 915-921, 2002.

[5] E. Ganjian and H. S. Pouya, "Effect of magnesium and sulfate ions on durability of silica fume blended mixes exposed to the seawater tidal zone," Cement and Concrete Research, vol. 35, no. 7, pp. 1332-1343, 2005.

[6] M. A. Bedoya, Efecto de los Agregados Reciclados y Cenizas de Carbón en la Durabilidad de un Mortero Ecológico Para su Aplicación en Arrecifes Artificiales, Ingeniería en Materiales y Procesos, Departamento de Materiales y Minerales, Universidad Nacional de Colombia, Bogotá, Colombia, 2015.

[7] M. Ayhan, H. Gönül, İ. A. Gönül, and A. Karakuş, "Effect of basic pumice on morphologic properties of interfacial transition zone in load-bearing lightweight/semi-lightweight concretes," Construction and Building Materials, vol. 25, no. 5, pp. 2507-2518, 2011.

[8] A. Elsharief, M. D. Cohen, and J. Olek, "Influence of lightweight aggregate on the microstructure and durability of mortar," Cement and Concrete Research, vol. 35, no. 7, pp. 1368-1376, 2005.

[9] X. Liu, H. Du, and M. H. Zhang, "A model to estimate the durability performance of both normal and light-weight concrete," Construction and Building Materials, vol. 80, pp. 255-261, 2015.

[10] H. Tanyildizi, "The investigation of microstructure and strength properties of lightweight mortar containing mineral admixtures exposed to sulfate attack," Measurement, vol. 77, pp. 143-154, 2016

[11] K. M. A. Hossain, S. Ahmed, and M. Lachemi, "Lightweight concrete incorporating pumice based blended cement and aggregate: mechanical and durability characteristics," Construction and Building Materials, vol. 25, no. 3, pp. 1186-1195, 2011.

[12] P. Spiesz, Q. L. Yu, and H. J. H. Brouwers, "Development of cement-based lightweight composites-part 2: durabilityrelated properties," Cement and Concrete Composites, vol. 44, pp. 30-40, 2013.

[13] H. Du, S. Du, and X. Liu, "Effect of nano-silica on the mechanical and transport properties of lightweight concrete," Construction and Building Materials, vol. 82, pp. 114-122, 2015.

[14] E. F. Irassar, V. L. Bonavetti, and G. Menéndez, "Cementos con material calcáreo: formación de thaumasita por ataque de sulfatos," Revista de la Construcción, vol. 9, no. 1, pp. 63-73, 2010.

[15] M. Lanzón and P. A. García-Ruiz, "Lightweight cement mortars: advantages and inconveniences of expanded perlite and its influence on fresh and hardened state and durability," Construction and Building Materials, vol. 22, no. 8, pp. 1798-1806, 2008.

[16] J. I. Tobón, O. J. Restrepo, and J. Payá, "Comparative analysis of performance of Portland cement blended with nanosilica and silica fume," Dyna, vol. 163, pp. 37-46, 2010. 
[17] O. Mendoza, G. Sierra, and J. I. Tobón, "Effect of the reagglomeration process of multi-walled carbon nanotubes dispersions on the early activity of nanosilica in cement composites," Construction and Building Materials, vol. 54, pp. 550-557, 2014.

[18] ASTM C127-15, Standard Test Method for Relative Density (Specific Gravity) and Absorption of Coarse Aggregate, ASTMInternational, West Conshohocken, PA, USA, 2015, http:// www.astm.org.

[19] ASTM C150/C150M-16e1, Standard Specification for Portland Cement, ASTM International, West Conshohocken, PA, USA, 2016.

[20] J.-C. Melgarejo, Atlas de Asociaciones Minerales en Lámina Delgada, Universidad de Barcelona, Barcelona, Spain, 2004.

[21] P. Vargas, O. Restrepo-Baena, and J. I. Tobón, "Microstructural analysis of interfacial transition zone (ITZ) and its impact on the compressive strength of lightweight concretes," Construction and Building Materials, vol. 137, pp. 381-389, 2017.

[22] Y. Ke, S. Ortola, A. L. Beaucour, and H. Dumontet, "Identification of microstructural characteristics in lightweight aggregate concretes by micromechanical modelling including the interfacial transition zone (ITZ)," Cement and Concrete Research, vol. 40, no. 11, pp. 1590-1600, 2010.

[23] D. P. Bentz, "Influence of internal curing using lightweight aggregates on interfacial transition zone percolation and chloride ingress in mortars," Cement and Concrete Composites, vol. 31, no. 5, pp. 285-289, 2009.

[24] Q. L. Yu, P. Spiesz, and H. J. H. Brouwers, "Development of cement-based lightweight composites-part 1: mix design methodology and hardened properties," Cement and Concrete Composites, vol. 44, pp. 17-29, 2013.

[25] T. Y. Lo, H. Z. Cui, W. C. Tang, and W. M. Leung, "The effect of aggregate absorption on pore area at interfacial zone of lightweight concrete," Construction and Building Materials, vol. 22, no. 4, pp. 623-628, 2008.

[26] J. Newman, B. S. Choo, and P. Owens, Advanced Concrete Technology Processes, Elsevier Ltd., New York, NY, USA, 2003.

[27] J. Newman and P. Owens, "2-properties of lightweight concrete," in Advanced Concrete Technology, pp. 3-29, Butterworth-Heinemann, Oxford, UK, 2003.

[28] ASTM C157/C157M-08(2014)e1, Standard Test Method for Length Change of Hardened Hydraulic-Cement Mortar and Concrete, ASTM International, West Conshohocken, PA, USA, 2014, http://www.astm.org.

[29] ASTM C 1012/C1012M-15, Standard Test Method for Length Change of Hydraulic-Cement Mortars Exposed to a Sulfate Solution, ASTM International, West Conshohocken, PA,2015, http://www.astm.org.

[30] S. Chandra and L. Berntsson, "6-lightweight aggregate concrete microstructure," in Lightweight Aggregate Concrete, pp. 131-166, William Andrew Publishing, Norwich, NY, USA, 2002.

[31] J. I. Tobón, J. Payá, and O. J. Restrepo, "Study of durability of Portland cement mortars blended with silica nanoparticles," Construction and Building Materials, vol. 80, pp. 92-97, 2015.

[32] R. Talero, "Expansive synergic effect of ettringite from pozzolan (metakaolin) and from OPC, co-precipitating in a common plaster-bearing solution: part I: by cement pastes and mortars," Construction and Building Materials, vol. 24, no. 9, pp. 1779-1789, 2010.

[33] R. Talero, "Expansive synergic effect of ettringite from pozzolan (metakaolin) and from OPC, co-precipitating in a common plaster-bearing solution. part II: fundamentals, explanation and justification," Construction and Building Materials, vol. 25, no. 3, pp. 1139-1158, 2011.

[34] ASTM C1157/C1157M-17, Standard Performance Specification for Hydraulic Cement, ASTM International, West Conshohocken, PA, USA, 2017, .

[35] ASTM C642-13, Standard Test Method for Density, Absorption, and Voids in Hardened Concrete, PA, USA, 2013, http:// www.astm.org.

[36] S. T. Lee, H. Y. Moon, and R. N. Swamy, "Sulfate attack and role of silica fume in resisting strength loss," Cement and Concrete Composites, vol. 27, no. 1, pp. 65-76, 2005. 


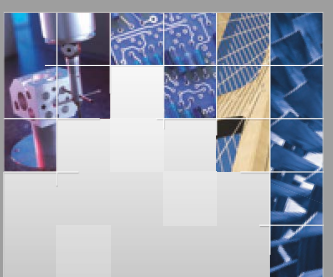

\section{Enfincering}
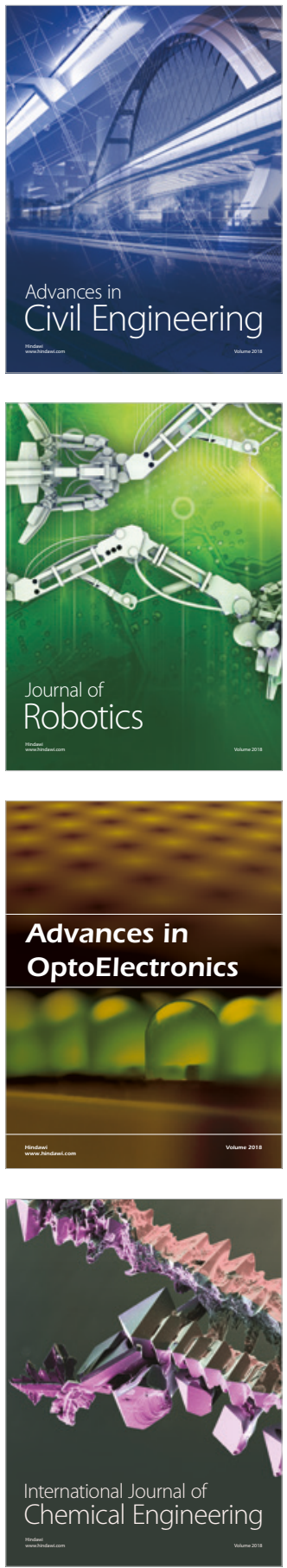

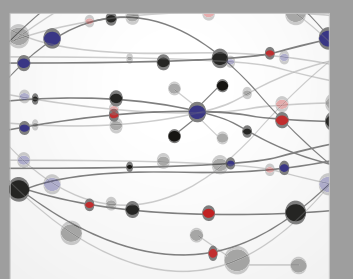

\section{Rotating \\ Machinery}

The Scientific World Journal

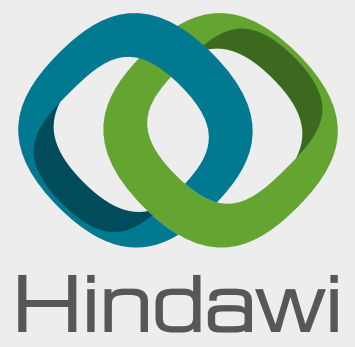

Submit your manuscripts at

www.hindawi.com
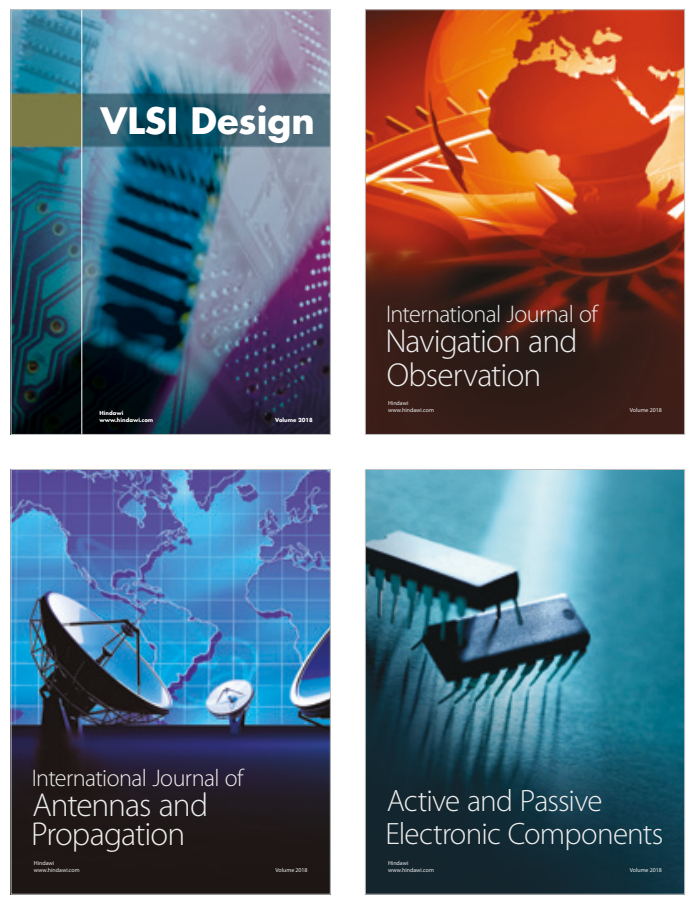
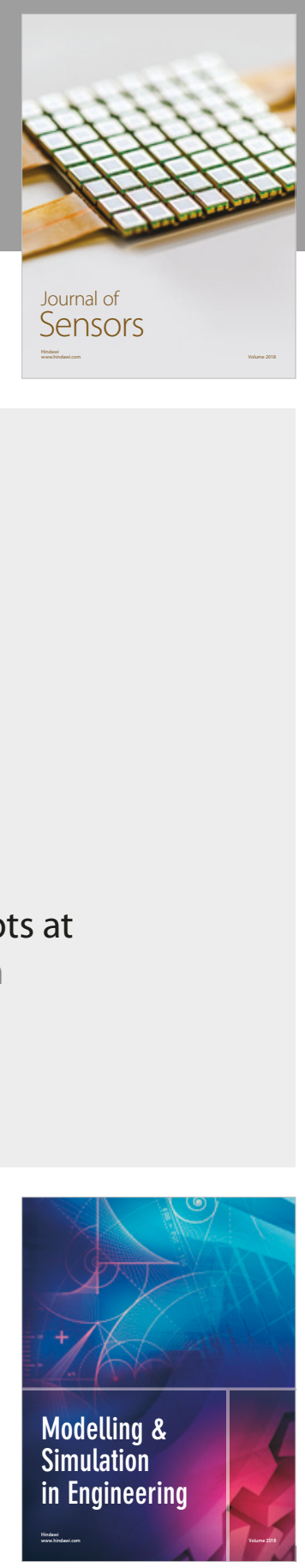

\section{Advances \\ Multimedia}
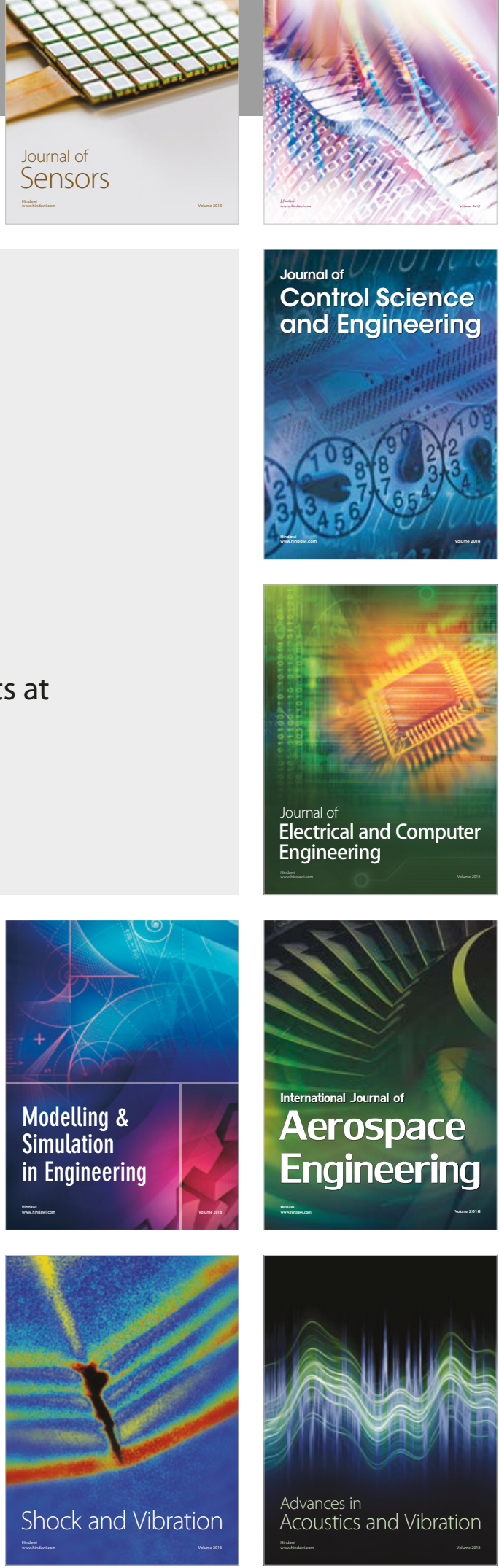